\title{
BMJ Open Cost analysis of the CTLB Study, a multitherapy antenatal education programme to reduce routine interventions in labour
}

\author{
Kate M Levett, ${ }^{1,2}$ Hannah G Dahlen, ${ }^{3}$ Caroline A Smith, ${ }^{2}$ \\ Kenneth William Finlayson, ${ }^{4}$ Soo Downe, ${ }^{4}$ Federico Girosi ${ }^{5,6}$
}

To cite: Levett KM, Dahlen HG, Smith CA, et al. Cost analysis of the CTLB Study, a multitherapy antenatal education programme to reduce routine interventions in labour. BMJ Open 2018;8:e017333. doi:10.1136/ bmjopen-2017-017333

- Prepublication history for this paper is available online. To view these files please visit the journal online (http://dx.doi org/10.1136/bmjopen-2017017333).

Received 24 April 2017 Revised 7 December 2017 Accepted 8 December 2017

\section{Check for updates}

${ }^{1}$ School of Medicine, University of Notre Dame Australia, Sydney, New South Wales, Australia

${ }^{2}$ National Institute for Complementary Medicines (NICM), Western Sydney University, Sydney, New South Wales, Australia

${ }^{3}$ School of Nursing and Midwifery, Western Sydney University, Sydney, New South Wales, Australia

${ }^{4}$ School of Midwifery and Community Health, University of Central Lancashire (UCLan), Preston, UK

${ }^{5}$ School of Medicine, Centre for Health Research, Western Sydney University, Sydney, New South Wales, Australia

${ }^{6}$ Research, Health Market Quality program, Capital Markets CRC, Sydney, New South Wales, Australia

Correspondence to

Dr Kate M Levett;

kate.levett@nd.edu.au

\section{ABSTRACT}

Objective To assess whether the multitherapy antenatal education 'CTLB' (Complementary Therapies for Labour and Birth) Study programme leads to net cost savings. Design Cost analysis of the CTLB Study, using analysis of outcomes and hospital funding data.

Methods We take a payer perspective and use Australian Refined Diagnosis-Related Group (AR-DRG) cost data to estimate the potential savings per woman to the payer (government or private insurer). We consider scenarios in which the intervention cost is either borne by the woman or by the payer. Savings are computed as the difference in total cost between the control group and the study group. Results If the cost of the intervention is not borne by the payer, the average saving to the payer was calculated to be $\$ A 808$ per woman. If the payer covers the cost of the programme, this figure reduces to $\$ A 659$ since the average cost of delivering the programme was $\$ A 149$ per woman. All these findings are significant at the $95 \%$ confidence level. Significantly more women in the study group experienced a normal vaginal birth, and significantly fewer women in the study group experienced a caesarean section. The main cost saving resulted from the reduced rate of caesarean section in the study group.

Conclusion The CTLB antenatal education programme leads to significant savings to payers that come from reduced use of hospital resources. Depending on which perspective is considered, and who is responsible for covering the cost of the programme, the net savings vary from \$A659 to \$A808 per woman. Compared with the average cost of birth in the control group, we conclude that the programme could lead to a reduction in birth-related healthcare costs of approximately $9 \%$.

Trial registration number ACTRN12611001126909.

\section{INTRODUCTION}

There has been a rise in rates of intervention during labour and birth in most countries, ${ }^{12}$ and intervention rates in Australia are well above the Organisation for Economic Cooperation and Development averages. ${ }^{3}$ Epidural rates in New South Wales hospitals have shown a rise over the past decade. In 2012, the state average for epidural block (EDB)

\section{Strengths and limitations of this study}

- This study is the first to demonstrate the cost savings that could accrue to payers from an effective antenatal education programme to reduce intervention rates in labour and birth.

- From the perspective of health economics, the use of Australian refined diagnosis-related group (ARDRG) codes, or similar international code, provides a relatively simple way to conduct cost analyses for particular interventions, enabling informed choices about the added value of a proposed intervention.

- The study examines the financial impact of reducing caesarean section (CS) for first-time mothers, and is timely given the global emphasis on reducing CS rates and the budgetary constraints faced by maternity providers in many settings.

- Limitations of this study include that the analysis is likely to be an underestimate of the actual amount of medical resources saved, as the current AR-DRG system does not capture the additional costs of procedures such as the provision of analgaesia and anaesthesia, which were significantly less prevalent in the study group.

- AR-DRG are limited, especially in the area of obstetrics, where we were unable to use the codes to quantify the cost savings related to the reduced rate of epidural block (primary outcome measure of the randomised controlled trial), and other common labour interventions, as they are all collapsed under the 'normal vaginal birth' code. The one-off costs of setting up were also not able to be included, and should be considered prior to implementation.

use was $46.5 \%$, with broad variation within the state, ranging from $15 \%$ to $82.7 \%$ depending on region and hospital. ${ }^{45}$ The high use of EDB for pain relief in labour has been identified as a contributing factor in rising rates of augmentation, assisted vaginal births and caesarean section (CS).$^{6-10}$

Childbirth education has also seen a shift away from birth preparation ${ }^{11} 12$ to a curriculum broadly centred on overall parent 
education. ${ }^{13}$ Findings from a systematic review on childbirth education indicated that antenatal education for childbirth or parenthood has a role in increasing feelings of self-confidence and agency, but they demonstrated little impact on reducing interventions and associated morbidity in labour. ${ }^{14}{ }^{15}$ Additionally, the Cochrane Systematic Reviews of individual complementary therapies have shown little impact on the use of epidural analgaesia and birth outcomes. ${ }^{16-19}$ This is with the exception of acupuncture which showed a reduction in overall pharmacological pain relief, and specifically epidural analgesia in two clinical trials, ${ }^{20}{ }^{21}$ when compared with placebo control or standard care, and a reduction in instrumental vaginal birth when compared with standard care. $^{19}$

Australian data suggest that complementary medicine $(\mathrm{CM})$ use is popular, ${ }^{22-24}$ and that $74.4 \%$ of women used some form of CM during pregnancy and $66.7 \%$ of these women also used non-pharmacological pain relief in labour. ${ }^{25}$ Building on this information, the Complementary Therapies for Labour and Birth (CTLB) Study was set up as an of an antenatal education programme of complementary therapies plus usual care, compared with usual care alone, for nulliparous women. ${ }^{26}$ We included several different therapies that had some evidence of effect for pain relief, ${ }^{1727-30}$ giving women, and their birth partners, the opportunity to choose from a variety of options during the course of their labour, as every woman and labour is different and the requirements throughout labour are changeable. Some therapies fitted more naturally with different women's attitudes, beliefs and physical characteristics. The study demonstrated a significant decrease in the use of epidural analgaesia and in other interventions during labour and birth for women in the study group compared with the control group. The study showed no particular statistical association of any one therapy with the outcome of epidural analgaesia, and women used an average of three to four different therapies throughout their labour. It was hypothesised that the effect was produced from an overall synergistic effect of the programme and the provision of choice and education for women and partners.

Previous research has shown the increased costs associated with different modes of birth, ${ }^{31-33}$ and the cascade of interventions associated with epidural use has been costed according to birth outcomes. ${ }^{34}$ Additionally, research using cost-effectiveness analysis has demonstrated equivalence of costs using international cost data for grouped outcomes associated with expectant management compared with immediate birth for the PPROMT Trial (Preterm Premature Rupture of Membranes close to Term). ${ }^{35}$ However, there is as yet no standard method of assessing the cost-effectiveness of a multitherapy programme that potentially affects multiple linked outcomes, as was the case in the CTLB study.

\section{METHODS}

The CTLB Study was a multicentre randomised controlled trial (RCT), where nulliparous women with a singleton, low-risk pregnancy between $24^{+0}$ and $34^{+6}$ weeks' gestation were randomly allocated to receive a 2-day antenatal education course plus usual care, or to usual care alone. Those allocated to receive the CTLB antenatal education course participated in a weekend workshop that focused on complementary therapy techniques for non-pharmacological pain relief methods for labour and birth and education about the physiology of normal labour and birth. Women were recruited to the trial via three sites at two hospitals in Sydney, Australia. The methods of the CTLB study, and the clinical and qualitative outcomes have been described in detail previously in Levett et al. ${ }^{2636}$ The primary outcome for the original RCT was epidural use for pain relief. Secondary outcomes included mode of birth, onset of labour, interventions during labour, pharmacological analgaesia use, any complications during labour or birth for the mother, any complications for the baby and admission to any special care units. In this paper, we focus on the analysis of costs, comparing costs in the study group with costs in the control group.

For the cost analysis, in each arm of the study the participants were assigned a single outcome for labour and birth, which was based on the highest level of intervention received during labour and birth. Each outcome was categorised according to the Australian Refined Diagnosis-Related Group (AR-DRG) codes, which groups together hospital admissions of the same clinical type that use similar amounts of hospital resources. This categorisation is a crucial step since hospitals are reimbursed the same amount for all admissions in the same AR-DRG group, although some small adjustments are usually made. Therefore, we costed each admission in the study by the average cost of admission in the corresponding AR-DRG. Each year, the Australian government publishes data regarding the average cost of admission for each AR-DRG. For this paper, we used the latest release, 'Round 18', for the financial year 2013-2014. ${ }^{37}$

This costing method was chosen because it correctly represents the medical cost incurred by the payer and because it could be used to make cost predictions to other comparable international systems with DRG-based payments. The rationale for this perspective is presented in the next section, together with a more detailed description of how the cost analysis was performed.

There are six relevant, mutually exclusive, AR-DRG categories that can be used to label the mother in-hospital stay for this study: O60C, O60B, O60A, O01C, O01B and O01A (table 1). However, none of the admissions in the study belonged to O01A or O60A, which denote births with catastrophic complications and major morbidity, which are extremely rare, such as embolism and severe complications of pre-eclampsia, such as Haemolysis, Elevated Liver enzymes, and Low Platelet count (HELLP) syndrome. While the algorithm to classify each birth in one of those codes is complex, generally 
Table 1 Australian Refined Diagnosis-Related Group (AR-DRG) codes and their meaning

\begin{tabular}{|c|c|c|}
\hline AR-DRG code & $\begin{array}{l}\text { Categorisation and intervention included in AR-DRG code (each category is } \\
\text { mutually exclusive) }\end{array}$ & $\begin{array}{l}\text { Average cost of } \\
\text { admission }(\$ A)\end{array}$ \\
\hline O60C & $\begin{array}{l}\text { This category includes women who had no intervention, or received any of the } \\
\text { following: received an induction of labour, augmentation of labour, epidural analgaesia, } \\
\text { narcotic pain relief and/or minor perineal trauma }\end{array}$ & 4832 \\
\hline O60B & $\begin{array}{l}\text { This category includes women who had any of the following: instrumental vaginal } \\
\text { birth with vacuum or forceps, had a postpartum haemorrhage, third-degree or fourth- } \\
\text { degree perineal tear, episiotomy or other 'non-severe' complications }\end{array}$ & 6423 \\
\hline O01B & $\begin{array}{l}\text { This category includes women who had a caesarean section with non-severe } \\
\text { complication, possibly associated with a blood loss greater than } 750 \mathrm{~mL}\end{array}$ & 11645 \\
\hline P68D & $\begin{array}{l}\text { Admission of neonate with minimal complications requiring observation for less than } \\
4 \text { hours }\end{array}$ & 2846 \\
\hline
\end{tabular}

Births are categorised according to the highest level of intervention. For example, a woman who had labour-induced (listed in O60C) but also had a postpartum haemorrhage (listed in O60B) would have the birth categorised as O60B.

speaking the codes $\mathrm{O} 60 \mathrm{C}(\mathrm{O} 01 \mathrm{C})$ and O60B (O01B) refer to vaginal (or caesarean) births without complications and with non-catastrophic complications, respectively. In cases of neonatal complications, where the neonate may need additional care, such as an admission to special care nursery or the neonatal intensive care unit, there are also AR-DRGs associated. For the births in this study, we only had information stating yes or no to any admission. Therefore, we applied only one AR-DRG of this category corresponding to the least complicated category of babies requiring observation for less than 4 hours, P68D. A more detailed clinical description of meaning of the four AR-DRGs for the mother's stay and the P68D AR-DRG is presented in table 1 together with the corresponding average cost of admission. To summarise, each birth is associated with only one of the AR-DRGs from the 'O' category corresponding to the highest level of intervention experienced during the birth, and may or may not be associated with the P68D AR-DRG.

\section{Cost analysis}

The key element of any cost analysis is the specification of which costs are included and for whom they accrue. The combination of these characteristics of the study defines the economic perspective taken. For example, if we were to take the payer perspective, we would only include the actual cost to payer (in this case the DRG payment) and possibly the cost of the programme, depending on whether we think this cost will be covered by the payer or the individuals. If we took the provider perspective, we would include as cost the actual amount of resources used by the hospital, minus the payment received by the payer, and again possibly the cost of the programme. The broadest perspective is the societal one in which it is irrelevant whom the costs accrue to and all healthcare costs are included, as well as non-healthcare costs (such as transportation or lost productivity) and intangible costs (such as pain and suffering). These three perspectives have been summarised in table 2 .
Since this study intends to inform health policy, it would be ideal to adopt a societal perspective. The largest cost component in this perspective is the medical resource use. We were not able to directly measure the resource use for each birth since that would have required a much closer collaboration with the hospital financial department and a degree of complexity that was simply not possible within the limited funding and scope of this pilot project. This limitation could be partially overcome by noticing that we only need to compare the average resource use in the intervention and control arms, and therefore the DRG costing method we have adopted, which is based on average costs, should provide a sufficiently close approximation of the actual resource use.

The next key cost to include in the societal perspective is the programme cost, and this poses no problem since it has been measured, as discussed in the section below.

Table 2 Stylised view of different economic perspectives (on the columns) and some of the costs they include

\begin{tabular}{llll}
\hline & Societal & Payer & Provider \\
\hline Medical cost (DRG) & & $\mathrm{X}$ & \\
$\begin{array}{l}\text { Medical cost (actual resource } \\
\text { use) }\end{array}$ & $\mathrm{X}$ & $\mathrm{X}$ \\
Programme cost & $\mathrm{X}$ & $\mathrm{X}(?)$ & $\mathrm{X}(?)$ \\
$\begin{array}{l}\text { Transfers/payments } \\
\text { Transportation and other direct } \\
\text { non-healthcare costs }\end{array}$ & $\mathrm{X}$ & $\mathrm{X}$ \\
$\begin{array}{l}\text { Lost productivity and other } \\
\text { indirect non-healthcare costs }\end{array}$ & $\mathrm{X}$ & \\
Intangible costs & $\mathrm{X}$ & \\
\hline
\end{tabular}

We outlined in green the costs measured in this study. The cost highlighted in blue is not measured, but it can be approximated by the DRG Medical Cost. The question marks mean that the cost may or may not be included, depending on how the programme is implemented.

DRG, Diagnosis-Related Group. 
However, as shown in table 2, in order to take a societal perspective, we would have also to include a number of costs that we have not been able to measure. For example, we would need to know how much the participants (and a birth partner, if they attended) spent in transportation, whether participation in the programme took time away from productive or leisure time, and whether additional costs were incurred in order to participate to the programme (eg, baby sitter, substitute caretaker). Given the 'pilot' nature of this study, the collection of these variables was simply out of scope. Therefore, we can only provide an approximated version of the societal perspective that only includes an approximation of the hospital resource use and the cost of the intervention, while it misses some of the costs incurred while participating in the programme.

However, if we adopt the payer perspective, we then have good estimates of the costs involved. In fact, the DRG-based approach correctly captures the payments of payers to hospitals, and we can consider two scenarios: one in which the cost of the programme is shouldered by the participants, and therefore not included in the analysis, and one in which it is included because it accrues to the payer. Therefore, the following analysis is set in the payer perspective. The savings in the payer perspective are most likely to provide an upper bound for those in the societal perspective since their calculation does not include additional costs associated with the intervention, such as transportation or lost productivity. In the following sections, we describe in details the calculations of the medical and intervention components of the costs.

\section{Medical cost}

We make the key assumption that the cost of an admission to the payer is well represented by the published average AR-DRG cost (see table 1). There may be corrections applied to the published figures that account for special circumstances, such as very long stays, but they tend to be rare and unlikely to play an important role in this analysis. All the births in the study can be assigned one of eight possible combinations of AR-DRGs (four ' $\mathrm{O}$ ' AR-DRGs and possibly the P68D AR-DRG), and for the purposes of this paper, we refer to each of the combinations as an AR-DRG class. The medical cost of an admission in an AR-DRG class is simply the sum of the average cost of the 'O' AR-DRG and the average cost of the P68D AR-DRG, if present, as shown in table 3. The medical cost per birth, in each arm, is the total medical cost divided by the total number of women in that arm. The total medical cost is equal to the sum of the medical costs over all the AR-DRG classes, which are computed by multiplying the number of women in each class by the average cost of birth for that class. The medical cost per woman is then obtained dividing total cost by number of women in the corresponding arm. In formulas:

$$
C_{\text {medical }}^{\text {treat }}=\frac{\sum_{\alpha} n_{\alpha}^{\text {treat }} C_{\alpha}}{N^{\text {treat }}} \quad C_{\text {medical }}^{\text {control }}=\frac{\sum_{\alpha} n_{\alpha}^{\text {control }} C_{\alpha}}{N^{\text {control }}}
$$

In this formula, $\alpha$ runs over the eight AR-DRG classes, $\mathrm{n}_{\alpha}^{\text {treat }}$ is the number of women in the treatment arm in each AR-DRG class $\alpha, \mathrm{C}_{\alpha}$ is the average cost of admission in AR-DRG $\alpha$ (shown in table 3) and $\mathrm{N}^{\text {treat }}$ is the total number of women in the treatment arm. Similar definitions hold for the control arm.

\section{Programme cost}

The programme is delivered by an educator to groups of six to eight participants, with each bringing at least one person to be a birth partner (referred to as the 'couple'), and it takes place over the course of 2 days of 7.5 hours each. Using an average number of participants equal to seven couples and a labour cost of $\$ A 35$ per hour for the educator, the labour cost per couple is equal to $\$ \mathrm{~A} 35 \times 7.5 \times 2 / 7=\$ \mathrm{~A} 75$. If one uses a more experienced educator, at an hourly rate of $\$ A 70$ rather than $\$ A 35$, the labour cost would rise to $\$ A 150$. For the purposes of this paper, we simply take the average of these two numbers, $\$ A 112$, and use $\$ A 75$ and $\$ A 150$ as lower and upper bounds in the sensitivity analysis. If the programme were administered to more (less) people, these costs would be lower (higher). However, the programme was designed to work for this group size, and it does not necessarily scale to a larger and smaller group. Therefore, we have not performed sensitivity analysis on the number of women attending a session.

The intervention also includes a small component of capital cost. In fact, each couple also receives a DVD (\$A12), a booklet (\$A2) and is provided with light refreshments (\$A15 over 2 days). We acknowledge that one may want to offer a more generous refreshment, valued at double that amount. Therefore, we estimate the refreshment cost by taking the rounded average between the two numbers, that is, $\$ A 23$, with a lower bound of $\$ A 15$ and an upper bound of $\$ \mathrm{~A} 30$ for the purpose of the sensitivity analysis. This leads us to estimate the capital cost at $\$ A 12$ $+\$ A 2+\$ A 23=\$ A 37$, with lower and upper bounds of $\$ A 29$ and $\$ A 44$, respectively.

We make the assumption that the programme is delivered in the hospital, and that the hospital always has spare capacity of one room for six to eight couples and an educator, and therefore do not include the cost of

Table 3 Eight possible Australian Refined Diagnosis-Related Group (AR-DRG) classes for this study and the corresponding average cost

\begin{tabular}{lllllllll}
\hline AR-DRG class & O60C & O60B & O01C & O01B & O60C+P68D & O60B+P68D & O01C+P68D & O01B+P68D \\
\hline Cost $(\$ A)$ & 4832 & 6423 & 9811 & 11645 & 7678 & 9269 & 12657 & 14491 \\
\hline
\end{tabular}




\begin{tabular}{lccc}
\hline Table 4 & Summary of programme costs \\
\hline & Minimum & Maximum & Estimate \\
\hline Educator cost (per hour) & 35 & 70 & \\
\hline No of hours (over 2 days) & & & 15 \\
\hline No of couples & & & 7 \\
\hline Educator cost per couple & 75 & 150 & 112.5 \\
\hline DVD & & & 12 \\
\hline Booklet & & & 2 \\
\hline Light refreshment (over 2 days) & 15 & 30 & \\
\hline Capital cost per couple & 29 & 44 & 36.5 \\
\hline Total programme cost & 104 & 194 & 149 \\
\hline
\end{tabular}

Costs included in the sensitivity analysis have 'Minimum' and 'Maximum' entries. Costs for which we assumed the uncertainty is negligible have only the 'Estimate' entry. All entries in \$A.

securing the space. This is an important assumption that takes advantage of the fact that the RCT was performed in a setting where the cost of space was 'sunk' (unless we want to include costs such as lighting/electricity that would be minimal). However, cost of space would be substantial if the programme were to be administered in a private setting, where a room had to be rented, or if the programme were scaled at a level that the hospital stops having spare capacity.

Therefore, the cost of the intervention in the setting of the current study was approximately $\$ A 112+\$ A 37=\$ A 149$ per woman, with a lower bound of \$A104 and upper bound of $\$$ A194. A summary of the programme costs is shown in table 4.

Who bears this cost and whether it should be included in the analysis depends on how one envisions this programme implemented and paid for. A possible scenario is one in which the cost of the programme is borne by the women participating, who would be paying for it out-of-pocket. Alternatively, depending on insurance arrangements, the payer might also be bearing the cost. In order to help readers find the scenarios they are most interested in, we will report the results as follows:

- We will report results in which the programme cost is met by the women;

- We will report the results in which there is no programme cost.

\section{Net savings}

The net savings to payers per woman delivered by the intervention are simply the difference between the medical cost in the control arm and the sum of medical plus programme cost in the treatment arm.

$$
S=C_{\text {medical }}^{\text {control }}-C_{\text {medical }}^{\text {treat }}-C_{\text {inter }}
$$

Our hypothesis for this study is that $S$ is positive and statistically different from 0 . We also consider the savings that would accrue to payers if the cost of the programme were borne by the woman. In this case, we do not include the cost of the intervention in the formula above and limit the analysis to the medical savings.

\section{Statistical analysis}

The statistical analysis was performed in R (V.3.3.2) and focused on the net savings variable $S$. We account for two sources of variation in the measurement of $S$ : the stochastic nature of birth outcomes, which drives variation in the hospital cost term $\mathrm{C}_{\text {medical }}^{\text {control }}-\mathrm{C}_{\text {medical }}^{\text {treat }}$, and the uncertainty in the cost of the intervention.

In order to model variation in medical costs, we used the plain bootstrap method ${ }^{38}$ ( $\mathrm{R}$ package 'boot') applied to the difference in medical costs between the study and control group, drawing a number of bootstrap samples equal to 500000 . Performing 'smooth' bootstrap, that is, adding a small amount of random noise to the data, did not lead to significant changes in the results. In order to model uncertainty in programme cost, we drew 500000 samples from the uniform distribution for the labour and capital components of the programme costs, using the lower and upper bounds described above. As a result, we obtained 500000 possible realisations of net savings that reflect both uncertainty in birth outcomes and in programme costs. The distribution of these 500000 figures is used in the next section to estimate the average net savings and the related CI. As a sensitivity test, we also performed a more traditional analysis using t-tests and reached the same conclusions of the bootstrap simulation method. The advantage of the bootstrap is that it allows visualisation of the distribution of the results and provides additional insights, such as the probability of experiencing any positive saving.

\section{RESULTS}

There are eight possible outcomes for the births in the study, corresponding to the four AR-DRGs for the mother, which may or may not be associated with a neonatal AR-DRG. Before showing the results for all eight outcomes, we show in table 5 an aggregate view that makes it clear why the study group had smaller costs than the control group. We divide all births according to whether a CS was performed or not. This corresponds to

Table 5 Summary of medical costs for intervention and control group by the type of birth: with and without caesarean section (CS)

\begin{tabular}{|c|c|c|c|c|c|}
\hline & $\begin{array}{l}\text { Birth } \\
\text { type }\end{array}$ & $\begin{array}{l}\text { Cost per } \\
\text { birth }\end{array}$ & $\mathbf{N}$ & $(\%)$ & $\begin{array}{l}\text { Overall cost per } \\
\text { birth } \\
(95 \% \mathrm{Cl})\end{array}$ \\
\hline \multirow[t]{2}{*}{ Intervention } & No CS & \$A6174 & 72 & 81.8 & \multirow{2}{*}{$\begin{array}{l}\text { \$A6930 (\$A6541 to } \\
\text { \$A7340) }\end{array}$} \\
\hline & CS & \$A10333 & 16 & 18.2 & \\
\hline \multirow[t]{2}{*}{ Control } & No CS & $\$ A 6336$ & 56 & 67.5 & \multirow{2}{*}{$\begin{array}{l}\text { \$A7739 (\$A7243 to } \\
\text { \$A8255) }\end{array}$} \\
\hline & CS & $\$ A 10647$ & 27 & 32.5 & \\
\hline \multicolumn{5}{|c|}{ Net medical savings per woman } & $\begin{array}{l}\text { \$A808 } \\
\text { (\$A163 to } \$ A 1455)\end{array}$ \\
\hline
\end{tabular}

The cost per birth is simply the average cost per birth, estimated over all the births in the corresponding category. 

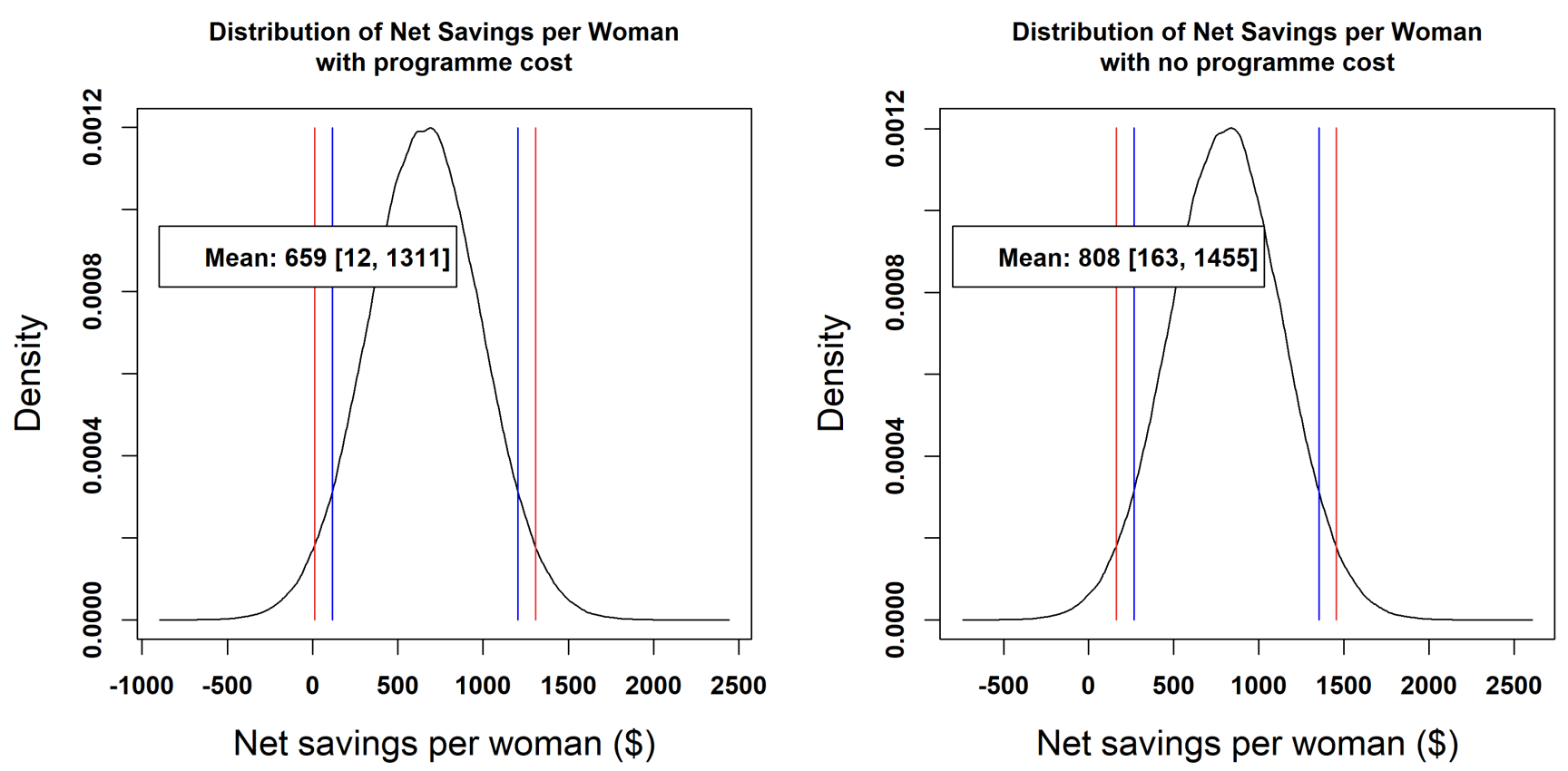

Figure 1 Bootstrapped distribution of the mean of net savings per birth, with (left) and without (right) programme costs. The blue and red lines denote the $90 \%$ and $95 \% \mathrm{Cl}$, respectively.

using the first three letters/digits of the AR-DRG for the mother's admission: O60 (no CS) or O01 (CS).

The key difference between the study and the control group is that the study group had a much lower rate of CS $(18.2 \%)$ than in the control group $(32.5 \%)$ (table 5$)$. Since CS births in this study cost approximately $\$ A 4200$ more than births without CS, it follows that the average cost of birth in the study group was $\$$ A808 less than in the control group, with a $95 \%$ CI of $\$ \mathrm{~A} 163$ to $\$ \mathrm{~A} 1457$. Therefore, if the cost of the intervention is borne by the woman, the payer saves an expected amount equal to \$A808 per woman.

If the payer covers the programme cost of $\$ A 149$ per woman, then the savings to the payer reduce to $\$ A 659$ per woman, with a CI of $\$ \mathrm{~A} 12$ to $\$ \mathrm{~A} 1311$.

Figure 1 shows the simulated distributions of the savings and costs per birth, with the red vertical lines showing the CI at $95 \%$ and the blue lines showing the CI at $90 \%$. The left side shows the net savings including the programme cost, while the right side only shows the medical savings.

We have reported the entire distributions of savings to payers because they provide information that goes beyond the usual mean and CI and provide a better picture of the financial risk borne by the payers. In the following section, we consider the case in which payers cover the programme cost, and therefore we refer to the distribution shown in the left panel of figure 1 . We consider four simple questions and provide the corresponding answers:

Q1: What is the probability that a payer experiences positive savings?

A1: It is the area of the distribution to the right of 0 , which is equal to $97.7 \%$.
Q2: Conditional on the payer experiencing positive savings, what is the expected value of those savings?

A2: It is $\$ A 677$, computed as the expected value of the distribution truncated to the right of 0 .

Q3: What is the probability that a payer experiences a loss (negative savings)?

A3: It is the area of the distribution to the left of 0 , which is equal to $2.3 \%$.

Q4: Conditional on the payer experiencing a loss, what is the expected value of the loss?

A4: It is $\$ A 122$, computed as the expected value of the distribution truncated to the left of 0 .

We can summarise these findings by saying that payers have a high probability $(97.7 \%)$ of experiencing positive savings (averaging at \$A677) and a small probability $(2.3 \%)$ of experiencing a loss (averaging at \$A122). We will come back to these figures in the context of sensitivity analysis.

The full distribution of outcomes and costs across all the eight possible outcomes is shown in table 6. A graphical representation is provided in figure 2, which shows the proportion of births, for study and control group, in the eight cost categories.

In figure 2, the cost categories are sorted in increasing order from left to right. The figure shows that the effect of the intervention was to shift some births from the more expensive categories to the less costly ones since there is a predominance of births in the intervention group (in blue) on the left side of the figure (the less costly outcomes).

\section{Sensitivity analysis}

This programme was implemented in a specific setting in a particular region of Australia. Other settings and 


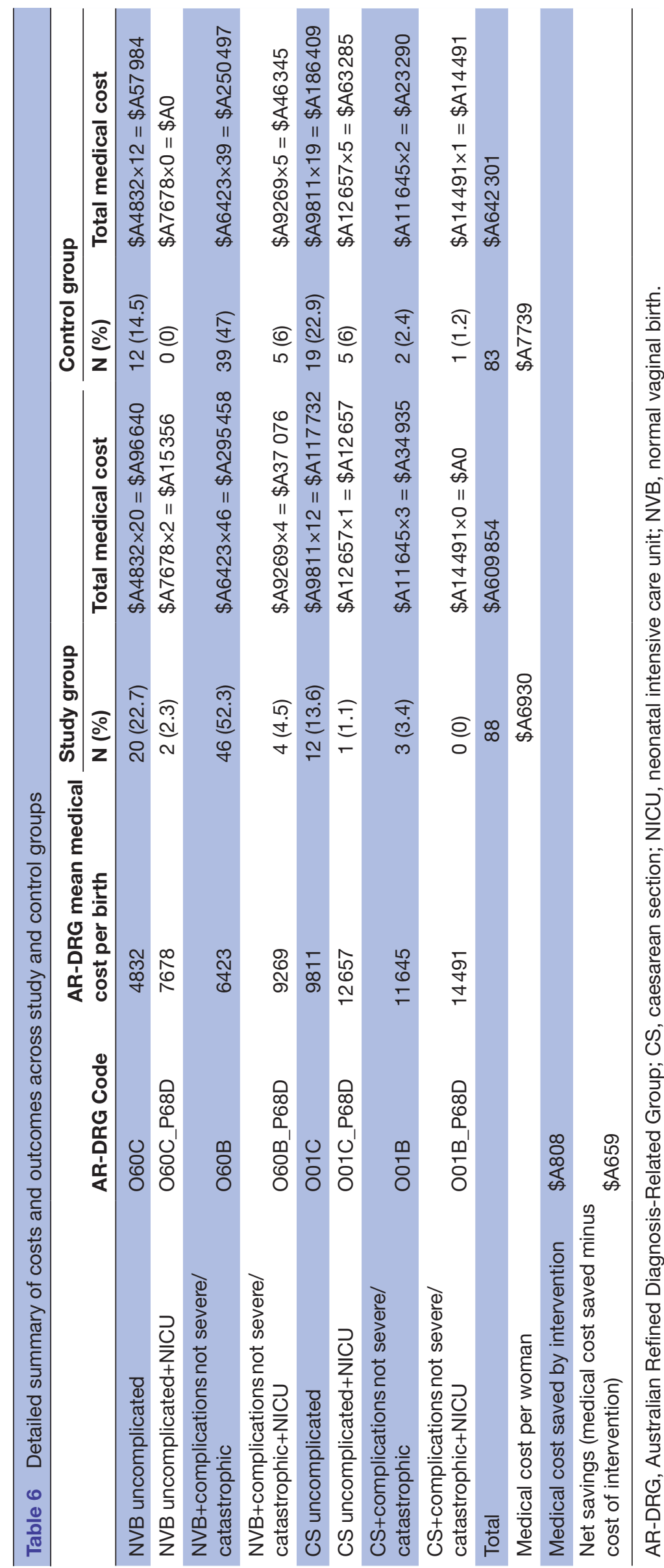

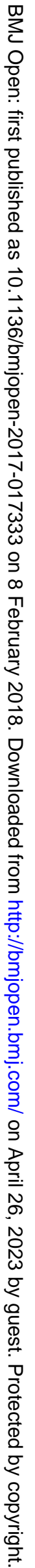




\section{$\%$ of cases by DRG combination}

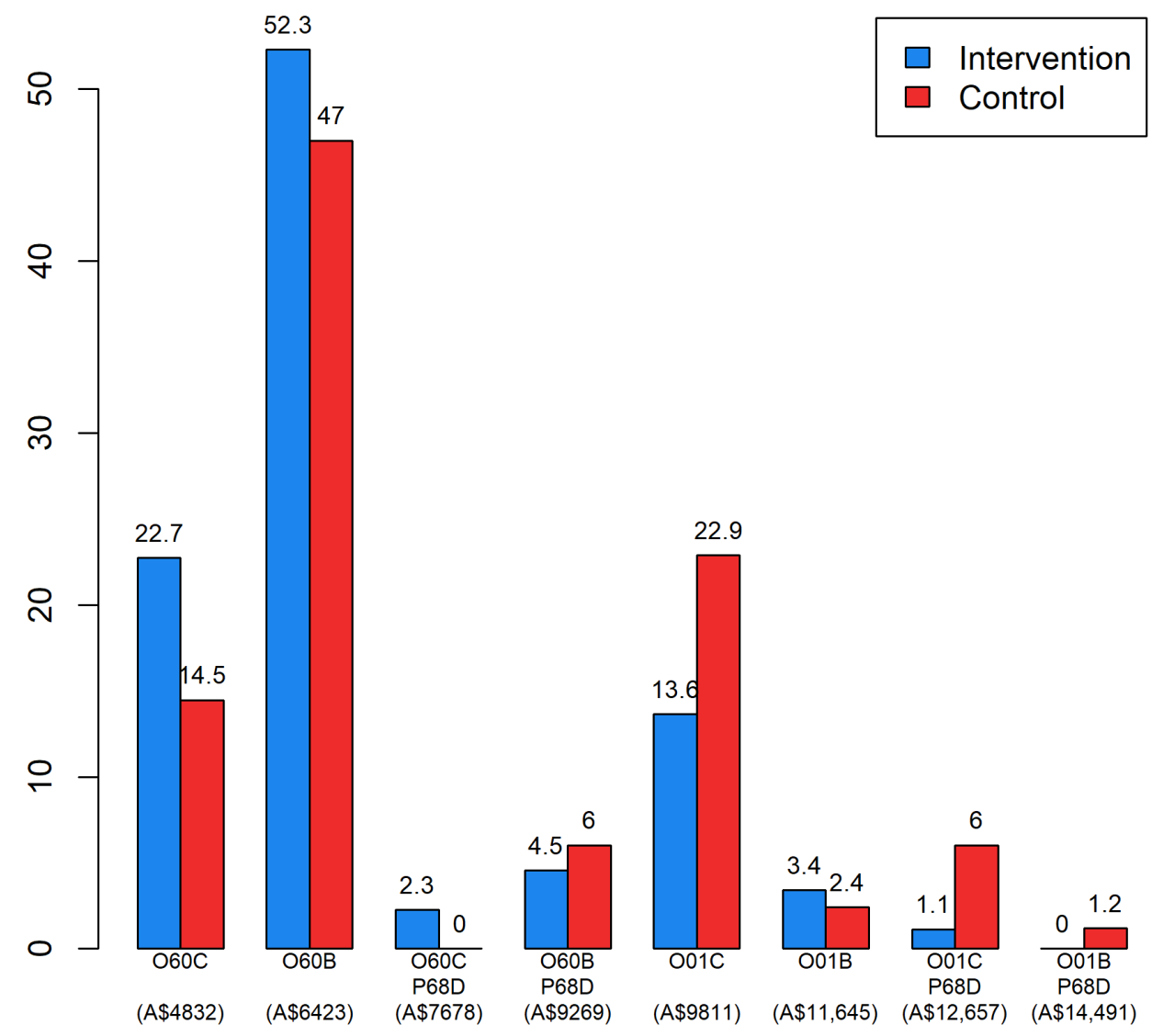

Figure 2 Proportion of births in each of the eight Australian Refined Diagnosis-Related Group (DRG) cost categories, for the control and the intervention group, sorted from lower to higher costs.

locations may imply different programme costs than the ones reported here. If additional programme costs are incurred, payers may have less of an incentive to adopt the programme, and therefore it seems important to explore the implications of higher-than-anticipated programme costs. An increase in programme costs of $\Delta \mathrm{C}$ dollars per woman reduces the expected savings per woman by $\Delta \mathrm{C}$ and alters the distribution of savings, decreasing the probability of any positive savings and increasing the probability of experiencing a loss. In the previous section, we reported information about the financial risk faced by payers by answering four questions. Here, we study how the answers to questions 1 to 4 are affected by an increase in programme costs. The results are shown in table 7 below.

The first line of the table simply reports the baseline case of the previous section. The following lines show scenarios of increasing programme costs. The additional costs were chosen in such a way that the probability of experiencing positive savings decreases smoothly from $97.7 \%$ to $90 \%$. The table shows that if actual programme costs are $\$ A 115$ more than the anticipated \$A149 (a 77\% increase), there is still a very high probability $(95 \%)$ of experiencing large positive savings (\$A580). Even if additional programme costs were as high as $\$ A 185$ (a $124 \%$ increase), the probability of observing positive savings is still $92.5 \%$, and the savings are still over $\$ A 500$.

Interestingly, as the programme costs grow from 0 to $\$ A 235$ and the probability of experiencing loss grow from $2.3 \%$ to $10 \%$, the expected loss, if realised, would only grow from $\$ A 122$ to $\$ A 155$. Stated differently, the expected loss, if experienced, is quite insensitive to increases in programme costs since for every additional dollar in programme cost, the potential loss only grows by 14 cents.

This analysis sheds some insights on how the results would look from a societal perspective. We have shown in an earlier section that, to the extent that DRG payments adequately capture the use of healthcare 
Table 7 Effect of additional programme costs (leftmost column) on the distribution of savings per woman

\begin{tabular}{|c|c|c|c|c|c|}
\hline $\begin{array}{l}\text { Additional } \\
\text { programme cost } \\
\text { (\$A) }\end{array}$ & $\begin{array}{l}\text { Probability of positive } \\
\text { savings (\%) }\end{array}$ & $\begin{array}{l}\text { Expected savings, } \\
\text { conditional on } \\
\text { positive savings } \\
\text { (\$A) }\end{array}$ & $\begin{array}{l}\text { Probability of loss } \\
(\%)\end{array}$ & $\begin{array}{l}\text { Expected loss, } \\
\text { conditional on loss } \\
\text { (\$A) }\end{array}$ & $\begin{array}{l}\text { Expected net } \\
\text { savings (\$A) }\end{array}$ \\
\hline 0 & 97.7 & 677 & 2.3 & 122 & 659 \\
\hline 115 & 95 & 580 & 5 & 136 & 544 \\
\hline 185 & 92.5 & 525 & 7.5 & 147 & 474 \\
\hline
\end{tabular}

The figures in columns 2 to 5 are the answers to questions Q1, Q2, Q3 and Q4 of the previous section. The last column shows the expected value of net savings.

resources, the societal perspective differs from the payer perspective because it should include additional societal costs. Table 7 above was developed to test additional programme costs, but it is also valid in the scenario in which programme costs are fixed at their baseline values and additional societal costs are included. Therefore, the table shows that if the sum of additional direct, indirect and intangible costs were somewhere between \$A100 and \$A200, there is still a high probability that society as a whole would benefit a non-negligible amount from the adoption of this programme.

\section{DISCUSSION}

This is the first study to demonstrate the cost savings that could accrue to payers from an effective antenatal education intervention using multiple therapies to reduce the use of routine clinical and pharmacological interventions in labour. The mean medical savings per episode of $\$$ A 808 , calculated to be more than $\$$ A97 million for the 120000 nulliparous births in Australia annually, are substantial and are likely to be an underestimate of the actual amount of medical resources saved. In fact, the current AR-DRG system does not capture the additional costs of procedures such as the provision of analgaesia and anaesthesia, which were less prevalent in the study group. Most of the medical savings in the model come from the reduction in the rate of uncomplicated CS in the women allocated to the antenatal programme. This was almost half the rate for those in the control group ( $14.7 \%$ vs $28.9 \%$ ). Given the global emphasis on reducing CS rates ${ }^{39} 40$ and the budgetary constraints faced by maternity providers in many settings, the potential benefits of this intervention may be significant from both a clinical and an economic perspective.

Implementation costs for the CTLB intervention are minimal as antenatal education classes are already offered to women (and their partners) as part of standard care in Australian hospitals that women pay for separately (usually between \$A100 and \$A300 depending on hospital and region). We have estimated costs of running the 2-day course to be $\$ A 149$ per woman, based on an average midwife rate of $\$$ A52 per hour and a small capital cost that includes DVDs and light refreshments (the actual midwife rate will be dependent on the level and experience of the midwife delivering the class). This compares very favourably when set against the medical savings of \$A808 per episode identified in this study.

From a health economics' perspective, the use of AR-DRG codes provides a relatively simple way to conduct cost analyses for particular interventions. This would enable commissioners and healthcare managers to make informed choices about the added value of a proposed intervention. Although the AR-DRG coding system is unique to Australia, DRG payment systems are widespread around the world and the model of assigning codes to represent specific, defined care packages is widely used. For example, The Healthcare Resource Group system employed in England and Wales incorporates similar codes to those used in Australia (UK Government, 2016). This has been demonstrated in a cost-effectiveness analysis of the Self-hypnosis for intrapartum pain (SHIP) Trial, an antenatal education programme of 'self-hypnosis for intrapartum pain' management in nulliparous women, conducted in the UK. ${ }^{41}$ The analysis was conducted from the perspective of the National Health Service (NHS) and Personal Social Services (PSSRU), where resource use and unit costs were obtained from the NHS and PSSRU databases. These costs were applied as an average cost per woman derived from overall unit costs. Where national coding systems are analogous, it may be feasible to compare intercountry, cost data for a given intervention, such as in the cost analysis of the PPROMT Trial. ${ }^{35}$

AR-DRG have the limitation of being a blunt instrument, especially in the area of obstetrics, and while they may reflect accurately the payer costs, they may not be as easily used to understand resource usage. In our case, for example, we were unable to use AR-DRG to quantify the cost savings related to the reduced rate of EDB. In fact, labour induction, labour augmentation, epidural analgaesia, episiotomy and minor perineal trauma are all included under code 060C (NVB uncomplicated), independently of whether the associated resources were used or not. 
Our analysis did not take into account the costs of setting up the programme, including training and insuring the staff who deliver it, or venue hire and staff transport. However, some of these costs are one-off, and therefore would become insignificant in a wider roll-out, while others really depend on how the programme is implemented and would require a careful analysis prior to implementation.

\section{CONCLUSION}

We have previously shown ${ }^{26}$ that the antenatal CTLB programme significantly reduces epidural use and CS in women assigned to the study group, as well as reducing a range of other clinical interventions that have important adverse consequences if overused in healthy women and babies. In this paper, we have shown that in addition to medical benefits, the CTLB programme is also associated with significant cost saving, largely related to a reduction in CS rates in the intervention group. This will be of interest to healthcare commissioners and providers.

The net savings to payers brought by the antenatal programme, not including programme costs, were estimated at $\$ \mathrm{~A} 808$ per woman. This figure drops to $\$ \mathrm{~A} 659$ when programme costs are included. Despite the relatively small size of the sample, the evidence is strong: computing the area to the right of the number zero in the simulated distributions of figure 1 , we estimated that the probability of observing any positive savings, even if programme costs were included, is $97.7 \%$.

Acknowledgements The original study that this analysis was based on can be found at BMJ Open. 2016;6(7):e010691. The authors wish to thank Christine Godkin, Anna Mashchenko, Kym Campradt and Lorica Health for kindly sharing their knowledge on the ICD and AR-DRG coding systems.

Contributors KML was the main contributor to the development, design and conduct of the study, and drafting and revision of the manuscript. FG is the health economist who designed and conducted the analysis for this paper, and drafting and revision of the manuscript. HGD provided mentoring, advice, editing and guidance on the design and manuscript for this study, and was the supervisor for the original overarching study. CAS provided mentoring, advice, editing and guidance on the design and manuscript for this study and was the main supervisor on the original overarching study. KWF and SD provided advice, editing and guidance for this study and review and editing of the manuscript.

Funding This article presents independent research, and the principal researcher is funded as a Research Fellow at the University of Notre Dame Australia, School of Medicine, Sydney. The project is supported through the Australian Government's Collaborative Research Networks (CRN) programme.

Competing interests As medical research institutes, the University of Notre Dame Australia, the National Institute of Complementary Medicine at the University of Western Sydney, the School of Midwifery at the University of Western Sydney, and the School of Midwifery and Community Health at the University of Central Lancashire (UCLan) receive research grants and donations from foundations, universities, government agencies, individuals and industry. The project that is the subject of this article was not undertaken as part of a contractual relationship with any organisation.

Patient consent Not required.

Provenance and peer review Not commissioned; externally peer reviewed.

Data sharing statement Additional data may be available on request by emailing kate.levett@nd.edu.au.

Open Access This is an Open Access article distributed in accordance with the Creative Commons Attribution Non Commercial (CC BY-NC 4.0) license, which permits others to distribute, remix, adapt, build upon this work non-commercially, and license their derivative works on different terms, provided the original work is properly cited and the use is non-commercial. See: http://creativecommons.org/ licenses/by-nc/4.0/

(C) Article author(s) (or their employer(s) unless otherwise stated in the text of the article) 2018. All rights reserved. No commercial use is permitted unless otherwise expressly granted.

\section{REFERENCES}

1. Gibbons L, Belizán JM, Lauer JA, et al. The global numbers and costs of additionally needed and unnecessary caesarean sections performed per year: overuse as a barrier to universal coverage. World Health Report 2010;30:1-31.

2. World Health Organization. 2015. WHO statement on caesarean section rates. Geneva: WHO, health Sar. Report No: WHO/ RHR/15.02 Contract No: WHO/RHR/15.02.

3. Bryant R. 2009. Improving maternity services in Australia: the report of the maternity services review. Canberra: Commonwealth of Australia. Contract No: Publications Number: P3-4946.

4. Centre for Epidemiology and Evidence. New South Wales mothers and babies 2010. Sydney: NSW Ministry of Health, 2012.

5. Dahlen HG, Tracy S, Tracy M, et al. Rates of obstetric intervention among low-risk women giving birth in private and public hospitals in NSW: a population-based descriptive study. BMJ Open 2012;2:e001723.

6. Anim-Somuah M, Smyth RM, Jones L. Epidural versus nonepidural or no analgesia in labour. Cochrane Database Syst Rev 2011:CD000331.

7. Roberts CL, Tracy S, Peat B. Rates for obstetric intervention among private and public patients in Australia: population based descriptive study. BMJ 2000;321:137-41.

8. Dahlen HG, Schmied V, Dennis CL, et al. Rates of obstetric intervention during birth and selected maternal and perinatal outcomes for low risk women born in Australia compared to those born overseas. BMC Pregnancy Childbirth 2013;13:100.

9. Green JM, Baston HA. Have women become more willing to accept obstetric interventions and does this relate to mode of birth? Data from a prospective study. Birth 2007;34:6-13.

10. NSW Department of Health. 2010. Maternity - Towards Normal Birth in NSW. Policy Directive. Sydney: Health NDo. Report No: 09/638-3 Contract No: PD2010_045.

11. Zwelling E. The history of Lamaze continues: an interview with Elisabeth Bing. J Perinat Educ 2000;9:15-21.

12. Zwelling E. Down memory lane: recollections of Lamaze International's first 50 years. J Perinat Educ 2010;19:11-16.

13. Svensson J, Barclay L, Cooke M. Effective antenatal education: strategies recommended by expectant and new parents. $J$ Perinat Educ 2008;17:33-42.

14. Gagnon AJ, Sandall J. Individual or group antenatal education for childbirth or parenthood, or both. Cochrane Database Syst Rev 2007:CD002869.

15. Jaddoe VW. Antenatal education programmes: do they work? Lancet 2009;374:863-4.

16. Smith CA, Collins CT, Crowther CA; Cochrane Pregnancy and Childbirth Group. Aromatherapy for pain management in labour. Cochrane Database Syst Rev 2011;114:CD009215.

17. Smith CA, Levett KM, Collins CT, et al. Relaxation techniques for pain management in labour. Cochrane Database Syst Rev 2011;12:CD009514.

18. Smith CA, Levett KM, Collins CT, et al. Massage, reflexology and other manual methods for pain management in labour. Cochrane Database Syst Rev 2012;2:CD009290.

19. Smith CA, Collins CT, Crowther CA, et al. Acupuncture or acupressure for pain management in labour. Cochrane Database Syst Rev 2011;36:CD009232.

20. Ramnerö A, Hanson U, Kihlgren M. Acupuncture treatment during labour - a randomised controlled trial. BJOG 2002;109:637-44.

21. Skilnand E, Fossen D, Heiberg E. Acupuncture in the management of pain in labor. Acta Obstet Gynecol Scand 2002;81:943-8.

22. Adams J, Easthope G, Sibbritt D. Exploring the relationship between women's health and the use of complementary and alternative medicine. Complement Ther Med 2003;11:156-8.

23. Adams J, Lui CW, Sibbritt D, et al. Attitudes and referral practices of maternity care professionals with regard to complementary and alternative medicine: an integrative review. J Adv Nurs 2011;67:472-83. 
24. Adams J, Sibbritt D, Lui CW. The use of complementary and alternative medicine during pregnancy: a longitudinal study of Australian women. Birth 2011;38:200-6.

25. Steel A, Adams J, Sibbritt D, et al. The influence of complementary and alternative medicine use in pregnancy on labor pain management choices: results from a nationally representative sample of 1,835 women. J Altern Complement Med 2014:20:87-97.

26. Levett KM, Smith CA, Bensoussan A, et al. Complementary therapies for labour and birth study: a randomised controlled trial of antenatal integrative medicine for pain management in labour. BMJ Open 2016;6:e010691.

27. Levett KM, Smith CA, Dahlen HG, et al. Acupuncture and acupressure for pain management in labour and birth: a critical narrative review of current systematic review evidence. Complement Ther Med 2014;22:523-40.

28. Field T, Figueiredo B, Hernandez-Reif M, et al. Massage therapy reduces pain in pregnant women, alleviates prenatal depression in both parents and improves their relationships. J Bodyw Mov Ther 2008;12:146-50.

29. Field T. Yoga clinical research review. Complement Ther Clin Pract 2011:17:1-8.

30. Jones L, Othman M, Dowswell T, et al. Pain management for women in labour: an overview of systematic reviews. Cochrane Database Syst Rev 2012;3:CD009234.

31. Clark L, Mugford M, Paterson C. How does the mode of delivery affect the cost of maternity care? Br J Obstet Gynaecol 1991;98:519-23.

32. Henderson J, McCandlish R, Kumiega L, et al. Systematic review of economic aspects of alternative modes of delivery. BJOG 2001;108:149-57.
33. Petrou S, Henderson J, Glazener C. Economic aspects of caesarean section and alternative modes of delivery. Best Pract Res Clin Obstet Gynaecol 2001;15:145-63.

34. Tracy SK, Tracy MB. Costing the cascade: estimating the cost of increased obstetric intervention in childbirth using population data. BJOG 2003;110:717-24.

35. Lain SJ, Roberts CL, Bond DM, et al. An economic evaluation of planned immediate versus delayed birth for preterm prelabour rupture of membranes: findings from the PPROMT randomised controlled trial. BJOG 2017;124:623-30.

36. Levett KM, Smith CA, Bensoussan A, et al. The complementary therapies for labour and birth study making sense of labour and birth-experiences of women, partners and midwives of a complementary medicine antenatal education course. Midwifery 2016;40:124-31.

37. IHPA. 2016. Australian public hospitals cost report 2013-2014 round 18. Australian: IHPA.

38. Efron B, Tibshirani RJ. An introduction to the bootstrap. Florida, USA: CRC press, 1994.

39. Betran AP, Torloni MR, Zhang JJ, et al. WHO Statement on Caesarean Section Rates. BJOG 2016;123:667-70.

40. Khunpradit S, Tavender E, Lumbiganon P, et al. Non-clinical interventions for reducing unnecessary caesarean section. Cochrane Database Syst Rev 2011:CD005528.

41. Downe S, Finlayson K, Melvin C, et al. Self-hypnosis for intrapartum pain management in pregnant nulliparous women: a randomised controlled trial of clinical effectiveness. BJOG 2015;122:1226-34. 